\title{
Sedimentological and lithostratigraphic study of the Foum El Kous Senonian, Central Hight Atlas of Morocco
}

\author{
Abdelouhed Farah $^{1 *}$, Ahmed Algouti ${ }^{1}$, Abdellah Algouti ${ }^{1}$, Fatiha Hadach ${ }^{1}$ and zahra Mourabit ${ }^{1}$ \\ ${ }^{1}$ University of Cadi Ayyad, Faculty of Sciences Semlalia, Department of Geology, Geoscience Geotourism Natural Hazards \\ and Remote Sensing Laboratory, BP 2390, 40000, Marrakech, Morocco
}

\begin{abstract}
The study area belongs to the southern edge of the central High Atlas. It is limited to the North by the Sub-atlasic accident and to the South by the extension of the Eastern Anti Atlas formations. To determine the depositional environments of the Senonian series, a sedimentological analysis of the facies was carried out based on field observations by the recognition of sedimentary structures and textures. An exoscopic analysis of the quartz grains was also carried out by a systematic prospecting of the grain relief and of all the characters that will appear on the surface of the grain after the formation of the mother rock at the origin place, during transport, immobilization phases and deposition. It seems very interesting to prospect for the clayey side in these Upper Cretaceous reddish formations because the evolution of the clayey and non-clayey assemblages in this central basin of the High Atlas will depend mainly on the combination of tectonic, eustatic, climatic and other influences. The Senonian of Foum El Kous which has a less important thickness corresponds to continental deposits that act the role of a natural barrier that separates on both sides the two sub-basins: Sidi Ali Oubork in the East and Ait youl in the West.
\end{abstract}

\section{Introduction}

The Senonian presents itself in Morocco under four facies [1], i). Into the fausse of the HAHA and the Khouribga region; it is a set of gray marl becoming yellow on outcrops and is also found in the Middle Atlas. ii) Along the two central massifs of the High Atlas as well as in eastern Morocco, we find a mixed regime with continental and lagoon formations preceding a marine series or alternating with marl and limestone marine formations. iii) Generally, a mixed regime that goes laterally to the East to a lagoon or lagoon-continental regime. This lateral passage is observed on two sides of the Western and Central High Atlas. It was not until 1963 that a synthesis of Ambroggi's work, which lasted about fifteen years, appeared in the form of a State Doctorate. His work concerned the southern part of the Western High Atlas and the Souss plain. He was able to bring stratigraphic precisions on the Senonian thanks to new paleontological discoveries based essentially on ammonite levels. He thus dated the Coniacian by Hemitissotia turzoi Karr and Plesiotissotia dullai Karr, the Santonian by Texanites texanum Roem, the Maastrichtian by Baculites sp, while the Campanian was dated only by microfauna, in the absence of ammonites. In 1975-1982, a team from the Geological Institute of the University of Bonn in collaboration with Wiedmann and his group [2-3] proposed a paleogeographic reconstruction of the Cretaceous, while summarizing the structural history of the Atlantic Gulf and its relation to the opening of the Atlantic Ocean, from the Triassic to the Cenozoic, and by giving a stratigraphic subdivision of the Cretaceous series. [4] highlighted the existence, in the Senonian, of a strongly subsident coastal sebkha to the East of the basin of Jbel Sour in the region of Ait Ourir (North Slope of the High
Atlas of Marrakech). In 1988, Ougarane studied two sections of the Senonian of the southern slope of the Western High Atlas, in the region of Imini (Gara Assaoud and Ste Barbe).

A paleogeographic history for the Senonian of the northern slope of the High Atlas of Marrakech, from Jbel Sour in the East to Imin'Tanout in the west, based on the study of facies, along with their depositional environment and their evolution in space and time were proposed [5].

\section{Methodology}

The sedimentological analysis of facies to determine the depositional media was carried out. In the field by the recognition of sedimentary structures and textures the principle of quartz otoscopy's is simple: each natural environment is characterized by a set of factors of various origins. Physical (pressure, temperature), chemical (concentration of dissolved silica in water, presence of iron hydroxides etc.), mechanical, wind or under water shocks, friction, grinding phenomena), biological (bacteria, diatoms), which leave on the surface of quartz grains some traces of various shapes and sizes characteristics of the factors that generated them. When the grains pass from one environment to another, these traces are exploited in a specific way according to the characteristics of the factors that generated them on the new environment. The analysis of these factors may soon determine the environments of the deposits of these clays and thus of the reddish formations in question.

\footnotetext{
*Corresponding author: farah6farah@gmail.com / abdelouhed.farah@ced.uca.ma
} 


\section{Geographical frameworks}

The study area belongs to the southern edge of the central High Atlas. It is limited to the North by the Sub-atlasic accident, to the South by the extension of the EaEV stern Anti Atlas formations (East Tinghir and West Imiter). Its access is by the road $\mathrm{N}^{\circ} 10$, linking the city of Ouarzazate and Er-Rachidia (Fig. 1).

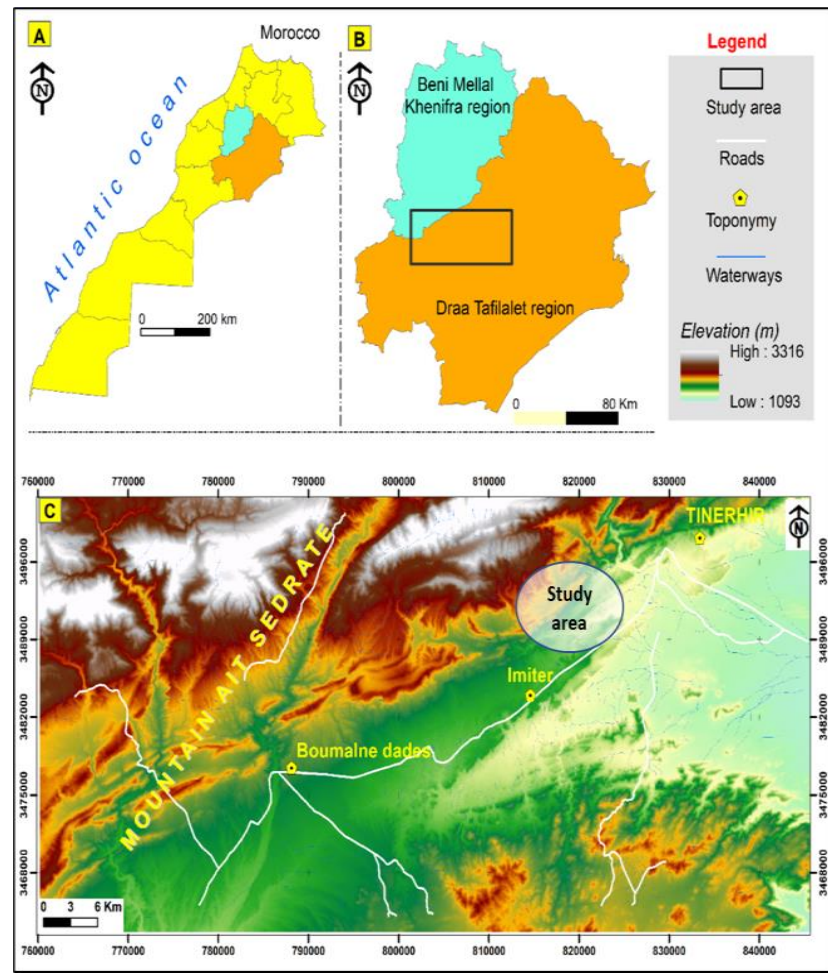

Fig. 1. Location of the study area: (A) Morocco, (B) the provinces of the regions of Deraa Tafilalet and Beni Mellal Ekhnifera and (C) the topographic map of the study area.

\section{Geological settings}

The zone that was the focus of this study is part of the furrow that has been individualized between the High Atlas and the Anti-Atlas (Fig. 2). Four zones can be identified [6], i) The Axial zone; it corresponds to the High Atlas reliefs and is composed of a rigid basement and a powerful Mesozoic cover of more than $2000 \mathrm{~m}$. Moreover, it is characterized by a system of horsts and grabens. This zone is limited to the south by the South Atlas Accident; ii) The Southern Sub-Atlasic zone, or Southern Atlasic Edge; it is formed by hills of highly deformed terrain straddling southwards, on Neogene and Quaternary deposits; in the Toundout region, the deformation of the edge is caused by gravity tectonics related to the uplift of the High Atlas [7] from the Upper Cretaceous [8], iii).

The Khelas zone; it corresponds to plateaus that extend over vast spreading plains and are constituted by Neogenic formations; the latter, locally involved in the folds of the South-Atlas Icrim, become tabular toward the south, where they are cut by wadis and covered by Quaternary formations [9], iv). The Anti-Atlas zone; it represents a stable domain formed of Paleozoic and Precambrian rocks on which rests in discordance a film of recent sediments.

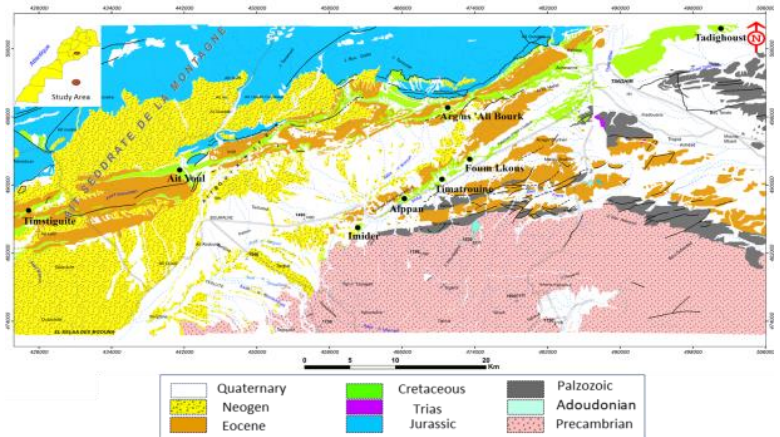

Fig. 2. Simplified geological map of the study area resulting from the mosaic digitalization of two extracts from two geological maps (Jbel Saghro Dades and Todgha in 1/200000, Minister of Energy and Mines, Directorate of Geology).

Structurally, the study area belongs to the southern flank of the Central Eastern High Atlas. It is constituted of pre-Cretaceous formations and is mainly composed of Jurassic, Triassic and Paleozoic materials (limestone and dolomite from the Aalenian and Dogger separated by the marly Toarcian). To the south, this structure ends in a straight tectonic line, called the South Atlasic fault or Atlastic accident (ASA), WSW-ENE oriented, morphologically materialized by numerous escarpments of fault lines with very steep cliffs separating it clearly from the southern zones. From a stratigraphic point of view, it is a subsident structure filled with various detrital sediments of Cretaceous age, of variable continental, lagoon and marine origin. This basin is presented as an asymmetric syncline, formed by sediments of Triassic age until recent formation.

\section{Results and Discussion}

\subsection{Foum El Kous cut}

The Foum El Kous cut was realized between the two villages Imider and Arg n'Sidi Ali Ou Bourk with a NW-SE direction. It is raised on the left bank of Assif n'Targuit, near the road leading to the mine of Imiter. GPS coordinates: N 31 $23^{\prime} 49.25^{\prime \prime}$ and $\mathrm{W} 5^{\circ} 44^{\prime}$ $12.71 "$

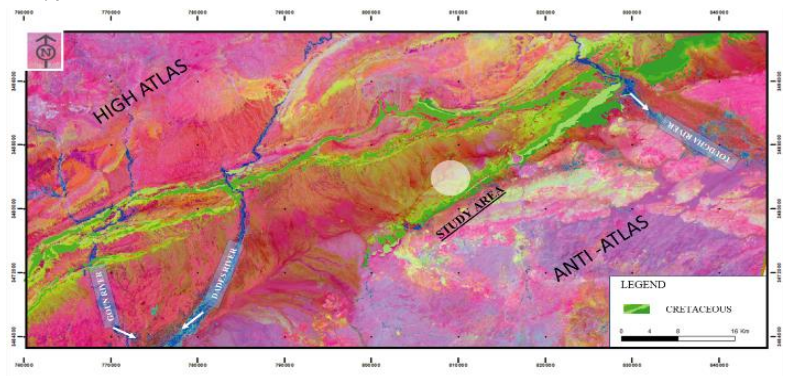

Fig. 3. Upper Cretaceous Alignments in the Study Area

\subsection{Sedimentological analysis}

The Senonian of Foum el kous is a formation about $150 \mathrm{~m}$ thick composed of red detrital sediments and is organized in sequences that are essentially sandstone at the base and silty at the top (Fig. 3). 
It contains 3 units: $\mathrm{U} 1, \mathrm{U} 2$ and $\mathrm{U} 3$. The $\mathrm{U} 1$ unit is delimited at the bottom by the Cenomano-Turonian bar with a thickness of 3 meters that ends with a perforated oxidized and full fossilized surface. It continues with an alternating strato-cropping of sandstone and red siltstones, but also some marl levels, the sandstone levels showing current ripples, Kerkoub concretions and a fine granulometry testifying to a fluvial continental hydrodynamics of medium energy (Figs. 3 and 4). Unit 2 begins with a 3meter-thick fine sandstone level with an erosive base, then current wrinkle and fenestrae figures that are well preserved in this level, followed by successive red clays 18 to 20 meters thick. In the middle part of unit 2 there are three sandstone bars that are 3 meters thick with a medium to fine grading then 18-meter-thick consolidated red clays sometimes friable. At the top of this unit the fine to medium grading sandstones are interspersed with small levels of clays and marls. Concerning unit 3 , in its lower part the whitish sandstone facies of the base show a horizontal stratification inclined towards the SW. Some levels are characterized by millimetric Kerkoubs concretions. At the top, the sandstone bars become red with oblique arcuate stratifications corresponding to channel-filling, intersecting bedding and Kerkoubs concretions. We also note the presence of some bioturbed levels. In its upper part, unit 3 is formed at the base by detrital levels thicker than those of the lower units. The sandstones are not very coarse and have carbonate cement (Fig. 8). They present erosive bases, channel fillings, intersecting laminations, centimetric zones affected by Kerkoub concretions, and oblique bedding prograding towards the SW. Towards the top, the base of the benches becomes increasignly erosive, the granulometry increases and the rock loses its initial texture through a total transformation into Kerkoub concretions. In general, the Foum El Kous section is characterized by a repetition of an elementary sandstone sequence that shows a decreasing granulometry aspect.

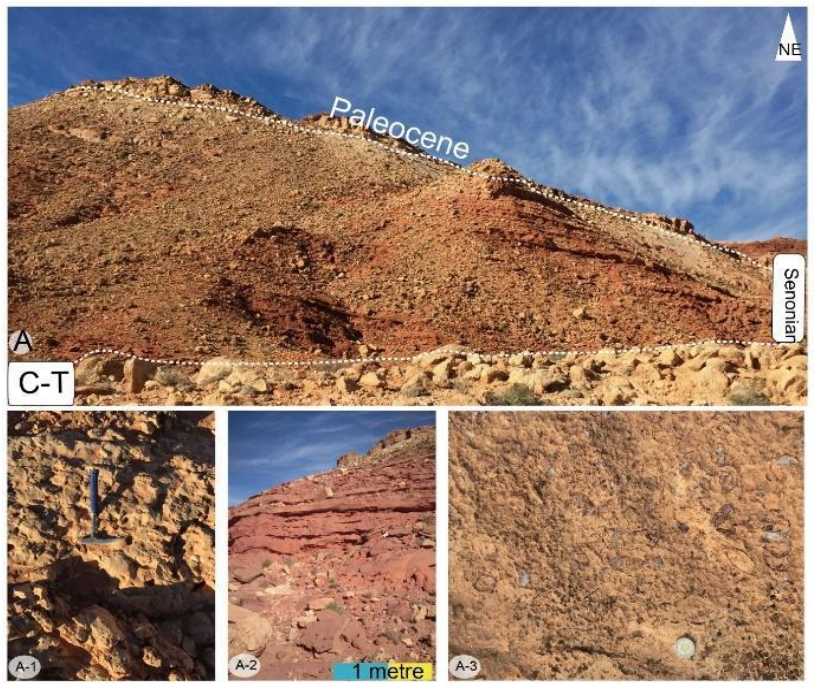

Fig. 4. Photos taken during field mission, A) General view of the Senonian strata with the lower CT bar as a lower marker and the Eocene-Paleocene bar as an upper marker of the Senonian series, A-1) oxidized ferruginous CT surface, A-2) alternating Senonian sandstone - silt clay, A-3) perforated oxidized Paleocene slab

The first term is coarse with a more or less erosive base deposited along a fluvial current (Fig. 5) of high energy, then the hydrodynamic energy of the medium decreases and we observe a deposit of fine term which shows floodplain deposits.

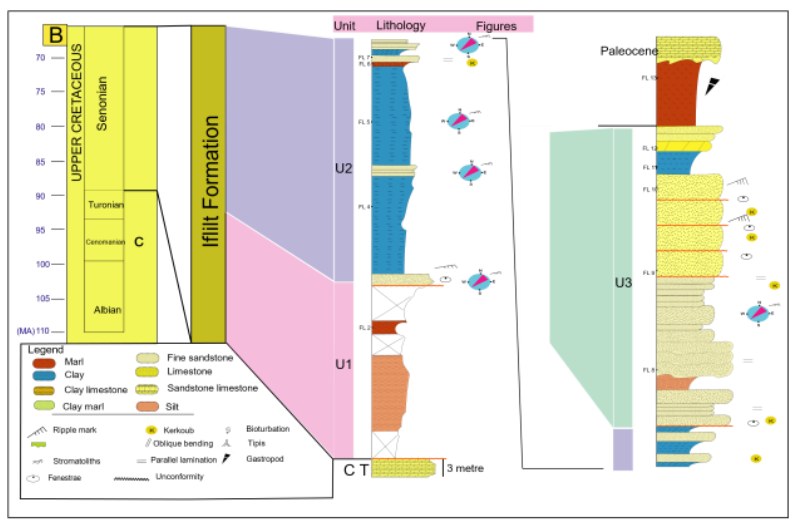

Fig. 5. Lithological stratigraphic column of the Foum el kous cut with some details on the section of the lithological units.

\subsection{Exoscopic investigation}

Exoscopy allowed to differentiate the sedimentary history of quartz (alteration, continental or aquatic transport). Examinations carried out using a scanning electron microscope on surfaces of these grains have allowed the identification of various figures that can be related either to the primitive crystalline network of quartz either with the corrosive actions proper to the alteration environment. The quartz grains underwent a complex evolution before their immobilization episode in the terrace. Many grains were carried by the winds, which is evidenced by the "crescents" of shock on the surface of the quartz. Other grains have the " $\mathrm{V}$ " shock that is evidence of a fluvial mobilization which is ensured by the waters of the wadi.

The traces of grazing generally testify to an evolution in an environment of high-altitude energy (division of these figures into several families of different orientations). The chemical alterations in this environment depend on the phenomena of emersion and immersion which alternate periodically. During emersion, the water trapped in the depressions becomes very concentrated in silica due to evaporation, which favors silica precipitation of different forms. The exoscopic study of quartz grains shows on the one hand the existence of several types of mechanical and chemical erosion, and on the other hand the presence of dissolution figures on the surface of several quartz grains. Thus, we can see that each grain with globular siliceous deposits is the witness of a fluvial transport of medium energy, which, because of their abundance and the absence of marks on their surface, have undergone only a very brief fluvial transport of medium energy. These are the quartz grains of samples namely A, B and C, which were probably evolved in a confined environment [10] Some grains show blunter edges (C) while others reveal traces of shocks as well as traces of V-shaped dissolution on the surface of the fractures (B and $\mathrm{C}$ ). The latter may correspond to 
traces of shocks and frictions between the grains in highenergy aquatic environments [11].

The Senonian series is characterized by a greater lithological variation, which leads to a variation in the sediment deposition environment and the dominant climate at that time. It is characterized by a semi-arid climate during the sedimentation period. These are proven by the presence of sharp-edged breaks (high-energy milieu fluvial $\rightarrow$ precipitation important $\rightarrow$ wet climate) and precipitation figures of silica (pedogenetic quartz) [12].
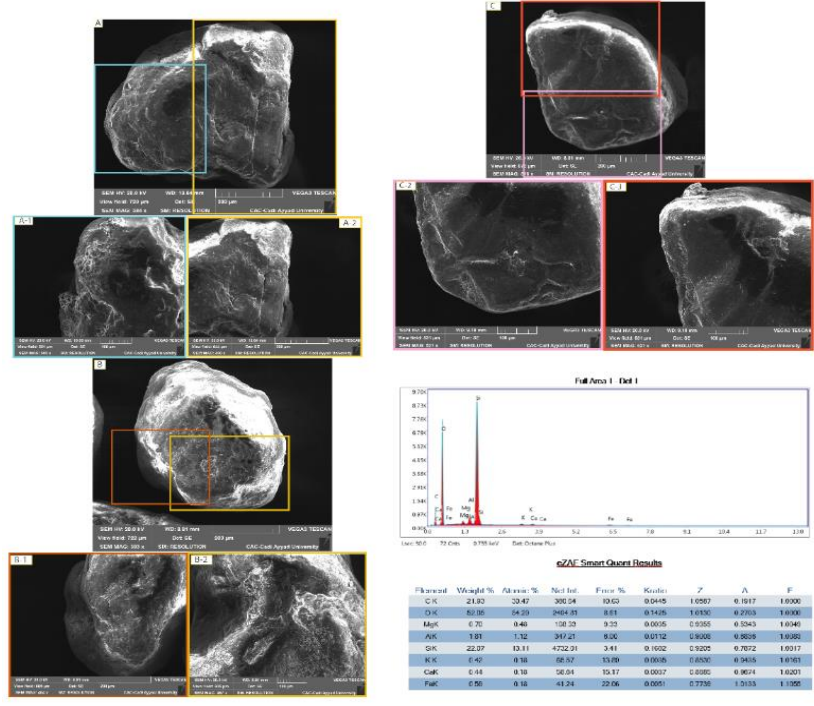

Fig. 6. Exoscopy of the quartz grains of the samples (A, B and C specimens of Foum el kous cut) Pi: Picking. C: Cracking. Eg: Erosive golf Sd: Solution depression's: Nail fracture. Ddsg: Depression. With silica deposit in Globules.Sn: Silica Nourishment. Nb: Nail break. V: Shock trace in v.

\subsection{Clay analysis}

$\mathrm{X}$-ray diffractometric analysis of the clay fraction allowed us to identify mainly smectite, kaolinite and illite peaks and others. These clay minerals are also associated with the following mineralogical species: quartz, calcite and other minerals. The clayey trains encountered at the Foum El Kous Cut (Fig. 7) show the omnipresence of illite, chlorite, kaolinite, vermiculite and palygorskite, with exceptional appearance of kaolinite (0-10\%), illite (0-20\%) and chlorite $(0-33 \%)$ in the first two units (U 1 and U2). The presence of illite suggests an active erosion of the hinterland and would probably come from the superficial alteration of preexisting phyllite minerals. Its association with kaolinite in most of the Senonian seems to indicate a fluvial contribution from the foothills [13].

On the other hand, the presence of chlorite could suggest an erosion of emerged domains with accentuated relief, which would thus come from the ante Jurassic series rich in chlorite [14]. The percentage of kaolinite is relatively low, which is essentially a mineral characteristic of the superficial alteration in acid leached environment. It is the existence of such an environment in hot and arid climate regions that justifies the abundance of kaolinite in the soil profiles [15]. However, kaolinite is associated with levels of siltstone and clay. Consequently, the origin of this kaolinite is probably detrital and would translate relatively declining reliefs under warm and relatively hydrolyzing climates. Muscovite mineral (0-30\%) is present in almost the entire section from the base to the top, which suggests several origins for its presence, for example neoformations or alterations of marine rocks (Jurassic) of High Atlas as sources of constituent elements of this type of mineral. Vermiculite and Palygorskite are characterizing the silty-clay in the unit U3. All this variation is related to a history of a relatively stable tectonically period and isolation of the environment under a hot and arid climate.
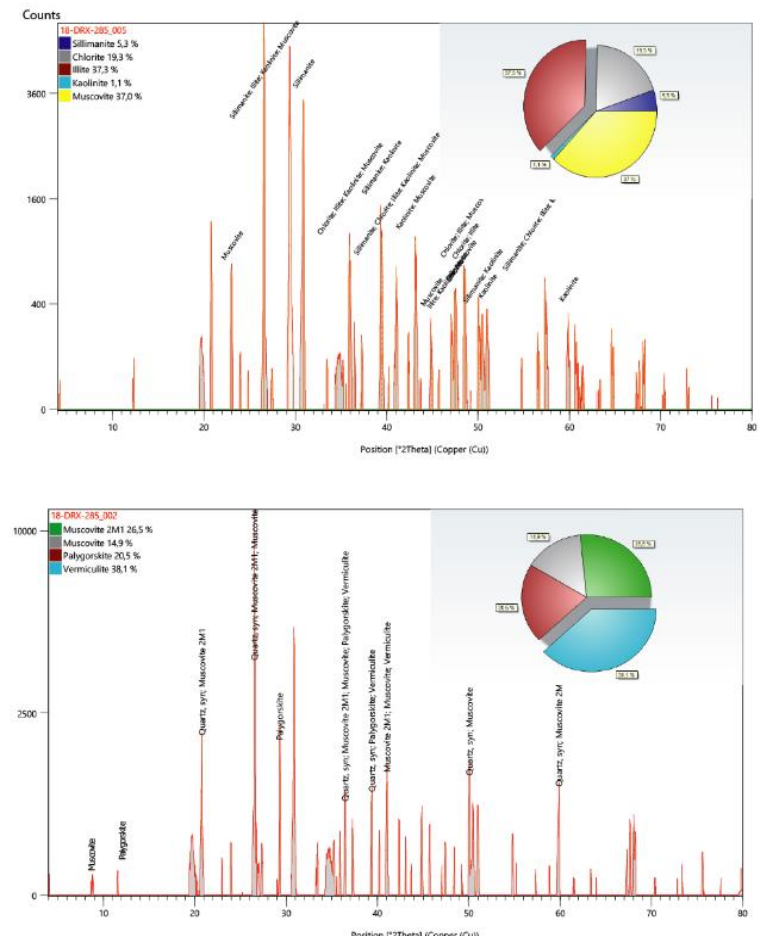

Fig. 7. Peaks and variations in percentage of clay minerals by High Score Plus software of the foum el kous section.

\section{Conclusion}

The results of the comparison of lithostratigraphic and paleoenvironmental data, the X-ray diffraction analysis of the clays and the exoscopic study of the quartz grains of the Senonian series of Foum El Kous suggest that it is the result of continental sedimentation, which forms a natural barrier separating the two small sub-basins on either side, Ait youl sub basin in the west and Arg nsidi Ali Oubourk sub basin in the east.

\section{Acknowledgements}

Our sincere thanks go to the Department of Geology and the Center of Analysis and Characterization of the Faculty of Sciences Semlalia Marrakech, Cadi Ayyad University, (Morocco) for guaranteeing all the exoscopic analyses of quartz and for the analysis of clays as well. The authors are very grateful to the anonymous reviewers for their valuable comments and suggestions and to the journal editor for a careful review of the article which helped to present work lucidly. 


\section{References}

1. R. Choubert, Du Dresnay, \& J. Hindermeyer - Google Scholar. https://scholar.google.com/scholar (1950)

2. M. Behrens, Geol. Rundschau, 67, 424-453, Jun. (1978), doi: 10.1007/BF01802799

3. J. Stets and P. Wurster, Geol. northwest African Cont. margin, 69-85, (1982), doi: 10.1007/978-3-64268409-8_5.

4. K. Azzaoui, (1986), Accessed : Jan. 04, 2021. [Online].

Available:

https://pascalfrancis.inist.fr/vibad/index.php?action=getR ecordDetail\&idt $=19612476$

5. A. Algouti, Accessed: Jan. 04, 2021. [Online]. Available

https://toubkal.imist.ma/handle/123456789/1834 (1991)

6. J. A., Jossen \& J. Filali Moutei. MOR/86/004Exploration des eaux profondes. Rapport Inédit, Rabat (1988)

7. R. Zylka, \& V. Jacobshagen, Berliner Geowissenschaftliche Abhandlungen, (A), 66, 415-432 (1986)

8. E. Laville, J.L. Lesage, M. Seguret, Geometrie, cinematique (dynamique) de la tectonique atlasique sur le versant sud du Haut Atlas marocain ; aperçut sur les tectoniques hercyniennes et tardi-hercyniennes. Bulletin de la Société géologique de France, 7, 527-539 (1977)

9. A. El Harfi. Doctorat, Université de Bourgogne, Dijon (1994)

10. J. Tricart, Loïc Le Ribault, Persée-Portail des revues scientifiques en SHS, 87, 201-202 (1978)

11. J. C. Flageollet, Cahiers ORSTOM, Série Pédologique, 18, 111-121 (1981)

12. N. Leneuf, Cah. ORSTOM (Géol.), 4, 53-65 (1972)

13. C. Sittler, \& G. Millot, Geologische Rundschau, 54, 333-343 (1964)

14. J. Beauchamp, A. Izart, \& A. Piqué. Can. J. Earth Sci, 28, 2024-2041 (1991)

15. G. Dunoyer de Segonzac. Sciences Géologiques, bulletins et mémoires, 29 (1969)

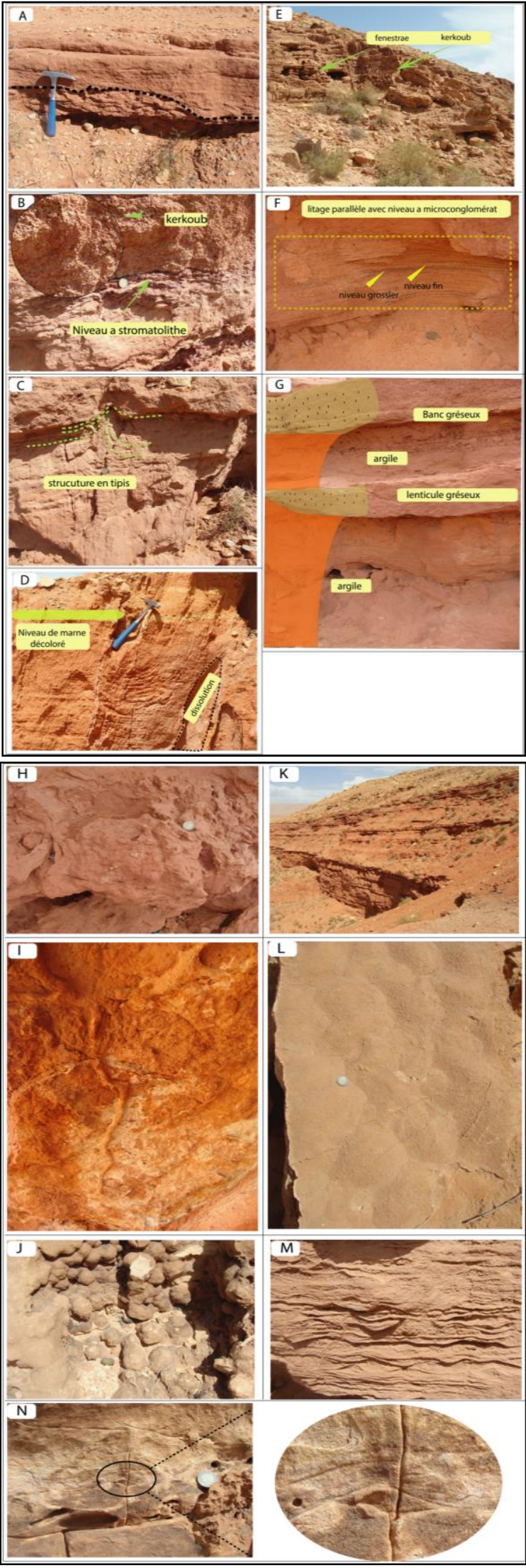

Fig. 8. Plate showing different photos of geological formations taken during field missions. details of some figures and some lithological facies of the Senonian of Foum el kous 